\title{
Obituary: Michael Brown
}

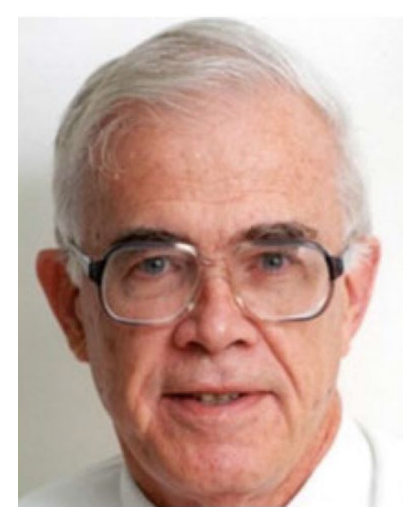

Professor Michael Ewart Brown

It is with great sadness that we have to inform you that Professor Michael Brown, the former ICTAC Secretary and founder member of the South African Thermal Analysis Group, passed away on Friday 31 May 2019, after a long and courageous battle with cancer.

Mike was an exceptional ICTAC Secretary over a period of some ten years, and he fulfilled many other roles within ICTAC including Publications Chairman, Affiliate Councillor and Leader of the ICTAC Kinetics Project and was a valued member of the Nominations Committee, Travel Fund Committee and Awards Committee. In all these positions, he gave exemplary and unstinting service, while always displaying tact and good humour, even under difficult circumstances. His outstanding contribution to ICTAC was recognised by the ICTAC Distinguished Service Award in 2008 and by the ICTAC Honorary Lifetime Membership in 2018. In his retirement, he was able to devote more time to his hobby of woodworking and a number of ICTAC Presidents (including those signing this obituary) were delighted to receive a gavel and sounding board, finely crafted from African hardwood, on taking office. These now form a priceless reminder of their good friend.

He spent the majority of his working life at Rhodes University, becoming Professor of Physical Chemistry and Dean of Science in 1986. He was a research scientist of exceptional ability, specialising in the decomposition of inorganic solids and the kinetics of solid-state reactions, and published over 130 papers and 5 books. His contribution to the field of solid-state kinetics and his fruitful collaboration with Professor Andrew Galwey of Queens University Belfast were recognised by a special edition of Thermochimica Acta in 2002, and their book "Thermal Decomposition of Ionic Solids" has become a standard work in the field. His dedicated service to the University was recognised by Vice-Chancellor's Distinguished Senior Research Award in 1998, and after his retirement, he was made a Distinguished Fellow of Rhodes University.

Mike was also an outstanding communicator, and the two editions of his book "Introduction to Thermal Analysis - Techniques and Applications" have provided countless thermal analysts with their first introduction to the field.

His work has been recognised by a number of awards including the Mettler Outstanding Achievement Award of the North American Thermal Analysis Society in 1996. The exactness, common sense and humour of the excellent Award lecture on kinetics that he delivered in Philadelphia are still in the memory of many participants at this ICTAC Congress. He also received the South African Chemical Institute's Gold Medal in 2000 and the NATAS Fellowship in 2003.

In spite of his many achievements, Mike was remarkably modest and his kindness and quiet sense of humour made him the best of company. He will be greatly missed by his many friends and colleagues worldwide. Our thoughts and heartfelt condolences go out to his wife Cindy and her family.

Edward Charsley and Jean Rouquerol

Publisher's Note Springer Nature remains neutral with regard to jurisdictional claims in published maps and institutional affiliations. 